DOI: http://dx.doi.org/10.22484/2177-5788.2017v43n1p71-97

\title{
Os valores-mesmos de veja
}

\author{
Wagner Belmonte
}

Resumo: Esta pesquisa investiga como o enunciador Veja apresenta a sociedade norte-americana como modelo a ser seguido e de que forma ela seleciona seus valores-mesmos. Os Mesmos são figuras enunciadas que reúnem as séries de paisagens socioculturais e políticas construídas pela mídia e homólogas à valorização média de seus públicos. Nos valores-mesmos estão as diretrizes do pensamento liberal norte-americano: capitalismo, liberalismo econômico e os pontos nodais liberdade e prosperidade. São afastadas do espaço dos valores-mesmos de Veja, por exemplo, as figuras do criminoso, sem-terra, árabe, do excluído e do miserável. O objetivo da pesquisa é compreender como a revista constrói, através dos pontos nodais, a ideia de que os EUA são um referencial para inspirar o Brasil como nação. Nossa tese é a de que o enunciador se apoia no espectro ideológico do liberalismo econômico para adotar posições conservadoras e tradicionais, sobretudo politicamente. Quanto à metodologia de pesquisa, ela se baseia na análise de discurso proposta por Laclau, Mouffe, Prado, e Charaudeau. A expectativa é que este trabalho contribua para aprofundar o debate sobre a forma como a relação BrasilEstados Unidos é apresentada, às vésperas de o título completar 50 anos.

Palavras-chave: Veja. Relação Brasil-Estados Unidos. Discurso.

\section{Veja's same values}

Abstract: This paper investigates how the enunciator of Veja presents the American society as a model to be followed, and in what way it selects its self-values. The same values are enunciated figures that gather a series of sociocultural and political scenarios constructed by the media, according to their public's average valuation. Whithin the valores-mesmos are the guidelines to the American liberal thought: Capitalism, Economic Liberalism and the nodal points, freedom and prosperity. The images of criminals, landless, Arabians, as well as excluded and miserable figures are all kept away from Veja's same values. The goal of this research is to understand how the magazine builds, through its nodal points, the idea that the USA are a reference to inspire Brazil as a nation. Our thesis is that the enunciator supports itself on the Economic Liberalism's ideological spectrum to adopt conservative and traditional positions, especially in the political sense. Regarding the research methodology, it is based on the discourse analysis suggested by Lacrau, Mouffe, Prado and Charaudeau. The expectation is that this work contributes to the deepen the debate about the way the relationship between Brazil and the USA is presented, on the eve of its 50 years anniversary.

Keywords: Veja. Brasil-United States relations. Discourse. 


\section{Introdução}

Há reportagens que contradizem a busca pela construção de um relato, esbarram e migram para uma esfera notadamente opinativa. Na concepção de José Luiz Aidar Prado (2013), a imprensa constrói a realidade, mas cada enunciador apresenta a sua visão como sendo a mais fiel possível ao interesse público. O poder do enunciador é o de ser quem relata o mundo a partir de sua autoconstrução enunciativa. Com isso, ele se firma e afirma como "todo-sabedor que esclarece o leitor o novo mapa do mundo" (PRADO, 2013, p. 30).

A linha editorial de Veja segue os valores do grupo editorial ao qual ela pertence. Entre eles, nas palavras do empresário Victor Civita, a liberdade de expressão e o desenvolvimento da livre iniciativa. "A Abril está empenhada em contribuir para a difusão de informação, cultura e entretenimento, para o progresso da educação, a melhoria da qualidade de vida e desenvolvimento da livre iniciativa e o fortalecimento das instituições democráticas do país" (ENTUSIASMO, 1990, p. 1).

$\mathrm{Na}$ construção de contratos comunicacionais com os leitores, o enunciador assume posições discursivas apresentadas de modo positivado ou, como define Prado (2013), se põe como sabedor. De acordo com Patrick Charaudeau (2009), para a construção do interesse social que o jornalismo pressupõe, todo discurso depende das condições específicas da situação de troca. "A situação de comunicação é como um palco, com suas restrições de espaço, de tempo, de relações, de palavras, no qual se encenam as trocas sociais e aquilo que constitui o seu valor simbólico" (CHARAUDEAU, 2009, p. 67). Segundo ele, as restrições são estabelecidas por regulação das práticas sociais que constroem convenções e normas de linguagens.

Charaudeau (2009) explica que o reconhecimento recíproco das restrições indica uma espécie de acordo prévio de dados. "Um contrato de reconhecimento das condições de realização de troca linguageira em que estão envolvidos: um contrato de comunicação" (CHARAUDEAU, 2009, p. 68). Segundo ele, este contrato resulta das características próprias à situação de troca, os dados externos, e das características discursivas decorrentes, os dados internos. Os dados externos "são aqueles que, no campo de uma prática social determinada, são constituídos pelas regularidades comportamentais dos indivíduos que aí efetuam trocas e pelas constantes que caracterizam essas trocas e que permaneceram estáveis por um determinado período" (CHARAUDEAU, 2009, p. 68). 
Os dados internos são discursivos, ou seja, permitem responder à pergunta "como dizer?”. Na concepção de Marcia Benetti (2007), a produção do texto jornalístico deve sempre levar em conta o posicionamento de dois parceiros - o jornalista e o leitor - e é preciso analisar as condições de troca em que esses parceiros se inserem. De acordo com ela, "Veja costuma assumir um tom de legitimidade, como se soubesse mais do que a população em geral e até do que as próprias fontes” (BENETTI, 2007, p. 42). É o que deixa claro Roberto Civita: “os políticos são treinados para mentir, isso é natural e aceito como um meio de evoluir no negócio deles. Então existe sempre a probabilidade de que um jornalista nosso, bem selecionado, bem treinado e bem pago, esteja com a maior parte da verdade (Grifo nosso)" (ROBERTO, 2013, p. 92).

Veja posiciona-se ideologicamente à direita - isso pode ser observado em muitas de suas reportagens. Um dos tantos exemplos diz respeito a seu enunciador ter reservas em relação aos direitos das minorias. Na reportagem "De braços cruzados" (DE, 1985, p. 85), edição do dia 24 de abril de 1985, a revista aborda a paralisação de metalúrgicos ${ }^{1}$ da Volkswagen, a maior montadora brasileira à época. Para deslegitimar a luta dos trabalhadores em greve, o enunciador recorre a uma ironia: “Os 37000 funcionários da Volkswagen do Brasil, a montadora número 1 do país, ocuparam todo o seu tempo na fábrica, na sexta-feira passada, em conversas amenas, jogos de dominó e leitura de jornais" (DE, 1985, p. 85).

Veja também subiu o tom na crítica a diversas greves que ocorriam no início da chamada Nova República, o período que envolve a vitória de Tancredo Neves no colégio eleitoral, a posse de José Sarney (em função da morte de Tancredo) e a eleição de Fernando Collor. Em 8 de maio de 1985, o enunciador dedicou capa ao tema (Fig. 1). A manchete trazia "O teste das greves" (O TESTE, 1985, p. 1) e a imagem de pessoas empunhando bandeiras da CUT (Central Única dos Trabalhadores), do MR8 (Movimento Revolucionário 8 de Outubro) e do PT (Partido dos Trabalhadores).

\footnotetext{
${ }^{1}$ Suas reivindicações: redução da jornada de trabalho para 40 horas semanas, trimestralidade dos reajustes e aumento de $4 \%$ acima do INPC - sem distinção de faixa salarial. A jornada oscilava entre 45 e 48 horas por semana.
} 
Figura 1 - Capa $O$ teste das greves, n870, 1985

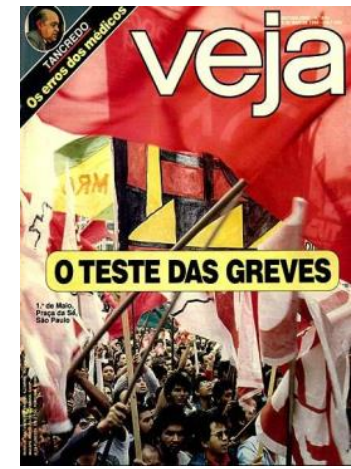

Fonte: Reprodução digitalizada de publicação impressa.

A matéria foi o principal destaque da editoria Brasil com a manchete "A febre paralisante" (O TESTE, 1985, p. 36). Nela, Veja relata que, desde 15 de março - quando o presidente José Sarney chegara ao Planalto -, 16 categorias tinham entrado em greve em nove Estados "fazendo com que 400000 trabalhadores cruzassem os braços (Grifo nosso)" (O TESTE, 1985, p. 36).). Em seguida, o enunciador diz que estes números são "modestos para países com larga tradição sindical (Grifo nosso)" (p. 36. Grifo nosso), mas revela descrença. "Na semana passada, era possível colher muitos outros indícios de que a visão de um Brasil imobilizado pelos sindicatos (Grifo nosso) ainda pertence ao mundo da fantasia” (p. 36). Nas linhas seguintes, ela apresenta a greve como problema, como indutora do prejuízo das indústrias e aposta que movimentos sindicais podem perder o fôlego rapidamente.

\footnotetext{
As profundas cisões existentes no movimento sindical não favorecem ações conjuntas - ao contrário, obrigam cada sindicato a valer-se de recursos próprios na tentativa de dobrar os empresários. Entregues à solidão, alguns deles sucumbem [...]. Os metalúrgicos do $\mathrm{ABC}$ e do Vale do Paraíba, por exemplo, mantêm-se em greve há 22 dias, reivindicando aumentos salariais, reajustes trimestrais e a redução da jornada de trabalho - itens que hoje frequentam praticamente todas as pautas dos sindicatos em greve. Na sexta-feira passada, o movimento dos metalúrgicos começava a dar sinais de que logo pode lhe faltar fôlego. Em contrapartida, as indústrias atingidas pela paralisação amargavam prejuízos num total de 3 trilhões de cruzeiros (O TESTE, 1985, p. 37).
}

O enunciador combate o que chama de sindicalismo radical. Dez anos depois, com a moeda estável e a inflação controlada, ela traria "FHC encara a CUT" (FHC, 1995, p. 32). Na pauta, a greve dos petroleiros. Segundo a revista, desde o final do governo do General João 
Figueiredo, sempre que os trabalhadores entravam em greve, o Planalto atendia alguns pedidos. Desta vez, o presidente estava irredutível.

Veja ultrapassa o nível do texto informativo e se coloca na posição de indicar, numa reportagem, que os caminhos adotados pelo presidente foram corretos para combater "sindicalistas, que não sabiam de que forma sair sem humilhação de uma greve que agrediu a lei e o cidadão comum" (FHC ENCARA, 1995, p. 32). Para ela, "o governo Fernando Henrique Cardoso mostrou firmeza, coerência e até competência” (p. 22). Na mesma reportagem, a revista cita que medidas semelhantes já tinham sido adotadas por países nos quais o governo pretendia reformar a economia. "Foi assim na Inglaterra de Margaret Thatcher, que deu impulso às mudanças depois de quebrar a espinha de uma gigantesca greve de mineiros. E também nos Estados Unidos, quando Ronald Reagan aceitou e venceu um desafio dos controladores de tráfego aéreo" (FHC PEITA, 1995, p. 32).

$O$ discurso ideológico segue forte, com direito inclusive à imagem de FHC como combatente. Na edição do dia 31 de maio de 1995, Veja associa o embate entre o sindicalismo e o governo como entrave à modernização do país (Fig. 2).

Figura 2 - Capa FHC peita a CUT, nº1394, 1995.

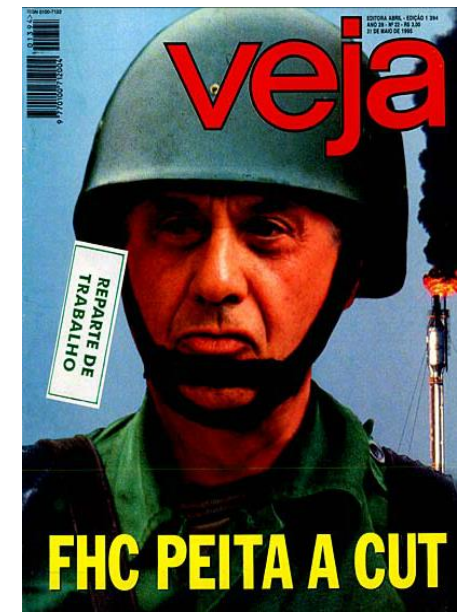

Fonte: Reprodução digitalizada de publicação impressa.

No miolo, a reportagem revela que Fernando Henrique Cardoso ordenou que 1.630 soldados do Exército ocupassem refinarias da Petrobrás. Segundo Veja, a explicação do ministro das Minas e Energia, Raimundo Brito, foi que a tropa fora mobilizada para "garantir 
os direitos de quem se dispunha a trabalhar" (FHC PEITA, 1995, p. 20). Em seguida, apresenta o discurso direto do comandante da $5^{\text {a }}$ Região Militar. "'Se tiver que atirar, vou atirar para manter a integridade das instalações', disse o general Antonio Araújo de Medeiros" (FHC PEITA, 1995, p. 20). De acordo com a revista, a intervenção foi "pacífica, e todas as pesquisas de opinião mostraram que a população apoiava a decisão do presidente em vestir o capacete" (FHC PEITA, 1995, p. 20). Já na edição do dia 14 de junho, Veja indica o caminho para o futuro. "O governo ganha fácil e abre caminho para mudar a produção do petróleo no Brasil" (O PLANALTO 1995, p. 30).

Veja, como se observa, amplifica um discurso liberal-conservador. Este campo, segundo Ernesto Laclau e Chantal Mouffe (2015, p. 50), "tem insistentemente argumentado que as sociedades ocidentais enfrentam uma crise de governabilidade e a ameaça de dissolução frente à ameaça igualitária". Neste caso, Laclau aponta que a luta da classe trabalhadora "forçara o capital a modificar sua composição interna e suas formas de dominação" (TRONTI apud LACLAU; MOUFFE, 2015, p. 148).

Ainda sobre o modo de construção empreendido por Veja em determinados temas, Prado explica que a mesmidade se refere, por exemplo, ao sucesso da livre iniciativa, ao galgar degraus na escala socioeconômica de posicionamento social, aos modelos aceitos pelas classes médias e altas como modalizadores típicos para o crescimento e sucesso pessoal e social.

Em 1986, Brasil e Estados Unidos enfrentavam uma crise diplomática e comercial por causa da regulamentação da Lei de Informática. Ao cobrir o assunto, Veja recomenda que seguir os passos dos norte-americanos, mais do que se modernizar, é romper com a vanguarda do atraso. Identificam-se nesta cobertura, os pontos nodais que totalizam, costuram um discurso que fala a essa classe média, não a todas as classes médias.

Denominamos articulação “qualquer prática que estabeleça uma relação entre elementos de tal modo que a sua identidade seja modificada como resultado da prática articulatória. A totalidade estruturada resultante desta prática articulatória, chamaremos de discurso (LACLAU; MOUFFE, 2015, p. 178). Segundo Laclau e Mouffe (2015), o discurso é também uma tentativa de dominar o campo da discursividade ${ }^{2}$ e deter o fluxo das diferenças, construindo um centro. Para isso, como explica Prado (2013), o discurso amplia as cadeias significantes que

\footnotetext{
${ }^{2}$ Para Laclau e Mouffe, este campo determina simultaneamente o caráter discursivo de qualquer objeto.
} 
buscam fixar os sentidos. De acordo com Prado, os pontos nodais fixam os sentidos ao criar a identidade de um discurso pela construção de um nó. Na concepção de Laclau e Mouffe (2015, p. 178), pontos nodais ${ }^{3}$ são “os pontos discursivos privilegiados desta fixação parcial”.

Fabio Alves Ferreira (2011) explica a Teoria do Discurso de Ernesto Laclau (Fig. 3).

Figura 3 - O discurso em Ernesto Laclau.

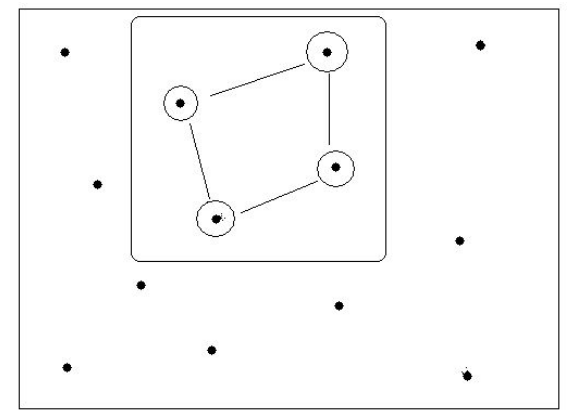

Fonte: Reprodução digitalizada de publicação impressa.

Ferreira explica como funciona a prática articulatória e a conexão desses diversos elementos-momentos que constituem o discurso.

1. Cada ponto é um ELEMENTO: diferenças sociais que não estão articuladas discursivamente. Isto pode acontecer, por não portarem demandas identificadas com outras demandas, na pluralidade de demandas do social.

2. Cada ponto no interior de um círculo é um ELEMENTO/MOMENTO: posições diferenciais que aparecem articuladas no interior de um discurso - a articulação de um momento num discurso, não impede sua articulação em outro discurso; desta maneira ele seria o mesmo elemento, entretanto teria sua natureza modificada de acordo com a articulação com outras identidades na formação de cada discurso. Por exemplo: identidades religiosas podem discutir o direito de acesso à terra, mas, pode também, está articulado numa outra prática discursiva na qual se coloca contra o direito de liberdade sexual.

3. Cada linha que liga os momentos é chamada de ARTICULAÇÃO: Os pontos nodais desenvolvem a função de fixar parcialmente o sentido. Essa fixação é parcial, pois o social tem essencialmente o caráter aberto, incerto, contingente, polissêmico.

4. O quadrado em torno dos elementos articulados é o DISCURSO: a totalidade articulada, resultante da prática articulatória e antagônica, plural de elementos/momentos hegemonizados (FERREIRA, 2011, p. 16-17).

\footnotetext{
${ }^{3}$ Laclau desenvolveu este conceito a partir da teoria de Jacques Lacan, que os chamava de points de capiton.
} 
É por este motivo que, como afirma Prado, a sociedade nunca conseguirá ser igual a si mesma, "pois a articulação constrói pontos nodais que fixam apenas parcialmente o sentido" (PRADO, 2013, p. 99).

A revista busca criar com seu leitor - revoltado com os entraves para o florescimento do liberalismo moderno - uma empatia. Para isso, Veja constrói o apelo da solidariedade. Ela enfatiza nas reportagens as alegrias e as frustações de seu público.

Para o enunciador, essa abertura comercial significa também liberdade, oportunidade e beneficia o consumidor. A sustentação narrativa é a de que o Estado brasileiro, como instituição, está diante da chance de romper com o atraso tecnológico e com a letargia anacrônica. É o que ocorre em "Sinais de boa vontade" (SINAIS, 1986, p. 108), reportagem publicada na edição de 10 de setembro de 1986, sobre a ida do presidente José Sarney aos Estados Unidos para tentar evitar a briga comercial no campo da informática.

De 1977, no governo do General Ernesto Geisel, a 1991, quando o país era governado por Fernando Collor de Mello, o Brasil planejou uma política de informática pensando em criar uma indústria local e obter tecnologia de ponta. Segundo Hideharu Carlos Ikehara, os Estados Unidos foram contra a reserva e desenvolveram um processo que ficou conhecido como “contencioso Brasil/Estados Unidos” (IKEHARA, 1997, p. 10). Baseado na Lei de Comércio americana $^{4}$, o conteúdo acusava o governo brasileiro de práticas desleais no comércio internacional. "Seu alvo era a política de informática. Este contencioso durou até junho de 1988 e resultou em severas retaliações comerciais americanas para com o Brasil” (IKEHARA, 1997, p. 10).

De acordo com Veja, o encontro de Sarney com Ronald Reagan era para discutir o inquérito, aberto pelo presidente americano em 7 de setembro de 1985, sobre "os danos que a aplicação da Lei de Informática pela SEI (Secretaria Especial de Informática) pudessem estar trazendo, no Brasil, às filiais das empresas americanas" (SINAIS, 1986, p. 108).

Além de duras e irônicas críticas à legislação brasileira, a publicação apresentava o Brasil como elo mais fraco, aludindo certa dependência ou subserviência ao mercado norteamericano. $\mathrm{O}$ enunciador indicava que o melhor roteiro que se desenhara em Brasília, em torno

\footnotetext{
${ }^{4}$ A seção 301 da Trade Act de 1974, autoriza o USTR (US Trate Representative) a adotar medidas contra qualquer ato, política ou prática que limite ou restrinja o comércio dos Estados Unidos com outras nações.
} 
dessa viagem, previa "voltar para casa sem a perspectiva próxima de ver o Brasil metido numa explosiva briga comercial com os Estados Unidos (Grifo nosso)" (SINAIS, 1986, p. 108). Para a revista, a intenção de negociar foi repassada a Washington, graças a canais abertos entre o Palácio do Planalto e a Casa Branca. E "o clima sombrio nas relações entre o Brasil e os Estados Unidos" (p. 108) poderia ser superado. Nas linhas seguintes, o enunciador Veja afirma os riscos às exportações brasileiras.

Às vésperas do embarque de Sarney, segundo assessores, seriam mais remotas as possibilidades de ocorrer o pior, como se vinha temendo cada vez mais nas últimas semanas, ou seja, que Reagan venha a adotar sanções contra as exportações brasileiras em represália às chamadas "práticas comerciais desleais" seguidas pelo Brasil na aplicação da reserva de mercado no campo da informática (SINAIS, 1986, p. 108).

O risco - alerta repetido - pode ser interpretado também como recomendação para que a estratégia nacional seja a de solucionar os problemas pela via da subordinação, evitando sanções às exportações brasileiras.

Se as represálias americanas se tornassem inevitáveis, segundo assessores do conselho econômico da Casa Branca, seriam atingidas preferencialmente as exportações brasileiras de calçados, suco de laranja e aço destinadas ao mercado dos Estados Unidos - o maior consumidor de tudo o que o Brasil vende no exterior e peça-chave para o equilíbrio da economia nacional (Grifo nosso) (SINAIS, 1986, p. 108).

Ao ressaltar a importância do mercado norte-americano para as exportações nacionais, Veja reafirma a posição subalterna da economia brasileira diante da maior economia do mundo, escolha assumida em praticamente toda a sua história. É uma forma de aceitação diante de um poder maior e difícil de enfrentar, por um lado, e dos interesses da elite local, de outro, que abocanhava benesses com essa posição.

De acordo com Prado (2006), os Mesmos são figuras enunciadas que reúnem as séries de paisagens socioculturais e políticas construídas pela mídia e homólogas à valorização média de seus públicos. São afastadas do espaço dos valores-mesmos de Veja, por exemplo, as figuras do criminoso, sem-terra, árabe, do excluído e do miserável. Nos valores-mesmos estão também as principais marcas e diretrizes do pensamento liberal norte-americano (Quadro 1). 
Quadro 1- Os valores-mesmos e os pontos nodais de Veja.

\begin{tabular}{|c|c|}
\hline OS VALORES-MESMOS DE VEJA & PONTOS NODAIS \\
\hline Capitalismo & Progresso/Liberdade \\
\hline Liberalismo Econômico & Modernidade/Desenvolvimento \\
\hline Economia Norte- Americana & Força/Vigor/Pujança/Inspiração \\
\hline
\end{tabular}

Fonte: BELMONTE (2016, p. 55).

Segundo Prado (2013), o discurso de Veja modaliza ${ }^{5}$ o agir do leitor quando o enunciador apresenta que o mundo é precisamente aquilo mesmo que ele descreve. "O reino mágico de Veja alerta para os perigos do mundo (veja o crescimento urbano, da violência, do crime, arme-se!)" (PRADO, 2013, p. 113).

Um exemplo ocorre em 2005, ano em que tivemos um referendo sobre a proibição do comércio de armas de fogo e munição. O eleitor decidiria, por meio de consulta popular em 23 de outubro ${ }^{6}$, os rumos do comércio de armas no Brasil. Na edição de 5 de outubro, Veja estampa “7 razões para votar NÃO” (7 RAZÕES, 2005, p. 1) - e crava, logo na capa, o seguinte argumento: "a proibição vai desarmar a população e fortalecer o arsenal dos bandidos" (Fig. 4).

A reportagem de miolo recebe o chapéu "Especial" e a manchete, "Referendo da fumaça" (7 RAZÕES, 2005, p. 77). O enunciador prescreve ao público meios para enfrentar a violência urbana e é enfático na defesa ao direito ao uso de armas. "VEJA acredita que a atitude que melhor serve aos interesses dos seus leitores e do país é incentivar a rejeição da proposta de proibição" (7 RAZÕES, 2005, p. 77).

\footnotetext{
${ }^{5} \mathrm{O}$ discurso modalizador é o que promove uma ação base nos verbos modais: poder, querer, dever, fazer, ser, explica Prado.

${ }^{6}$ No dia 23 de outubro de 2005, depois de um intenso debate popular, 59 milhões de brasileiros (63\% dos eleitores) foram às urnas e rejeitaram a proibição da venda de armas de fogo e munições em um referendo.
} 
Figura 4 - Capa 7 Razões para votar NÃO, n¹925, 2005.

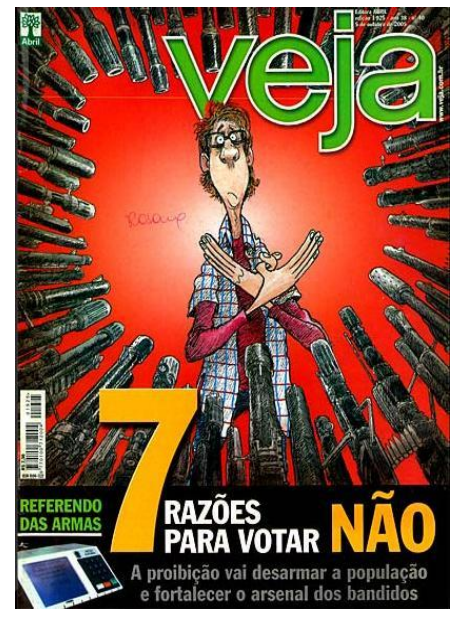

Fonte: Reprodução digitalizada de publicação impressa.

O que motiva essa afirmação do direito de estimular o cidadão a comprar e ter uma arma? Além do argumento de livre escolha, por si só questionável neste caso, existe um pressuposto de que a sociedade dos vencedores, de quem batalha todos os dias para chegar lá, tem de encontrar meios de agir por si própria para se proteger da criminalidade. Este cenário permite um paralelo com o que o sociólogo Boaventura de Sousa Santos (1998) aponta como "fascismo social".

Na sociedade do fim do século, o Estado de natureza é a desestabilização total das expectativas das classes populares, ansiedade permanente da grande maioria em relação a presente e futuro, caos permanente nos atos mais simples de sobrevivência ou convivência. A ampliação de "Estados de natureza", dos quais não se tem a opção individual ou coletiva de sair, configura uma crise de tipo paradigmática, epocal. É, pois, situação de muitos riscos. Julgo que todos se podem resumir num só: a emergência do fascismo social (SANTOS, 1998).

Santos (2003) define o fascismo como "um regime social, um sistema de relações sociais muito desiguais que coexiste cumplicemente com uma democracia política socialmente desarmada". O fascismo social, segundo ele, "é a extrema polarização da riqueza em muitos países" (SANTOS, 2001). Para o sociólogo, o Brasil é um bom exemplo de sociedade democrática que convive com fascismo social. 
[...] o Brasil está criando uma forma de convivência semelhante à produzida pelas sociedades fascistas tradicionais. É a convivência com o medo, o colapso total das expectativas, que é o fato de a pessoa viver sem saber se amanhã estará viva, se terá emprego, se terá liberdade (Grifo nosso). Esse tipo de convivência fascista não está sendo produzido por um Estado fascista: o Estado é democrático, há partidos, há assembleias, há leis, há instituições públicas. Simplesmente há uma população, cada vez maior, que não tem acesso a esses direitos (SANTOS, 2001).

A associação que Veja estabelece é a de que nos Estados Unidos o porte de armas está diretamente relacionado à conquista da liberdade individual. De acordo com a antropóloga Tereza Caldeira (2008), a construção discursiva da revista sobre crime divide o mundo entre o bem e o mal. E criminaliza certas categorias. O enunciador observa com naturalidade a tendência da classe média se armar.

Nas duas capas a seguir (Fig. 5 e Fig. 6), publicadas com um intervalo de 15 anos, há a indicação de autodefesa na edição de 1984 e de sensação de segurança na de 1999. Figura 5 - Capa O Brasileiro,
se arma, n'822, 1984.

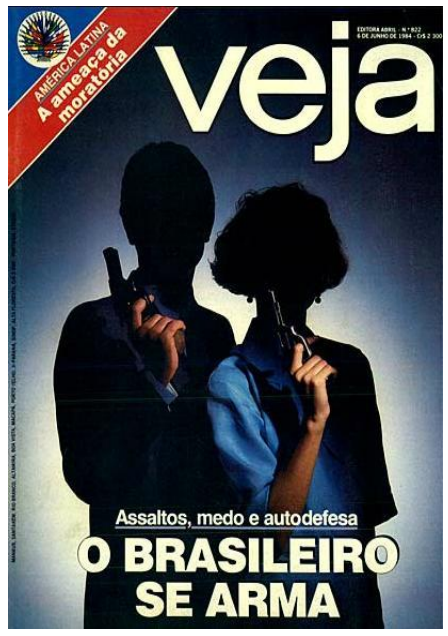

Figura 6 - Capa Armas - ter ou não o ter?, n¹603,1999.

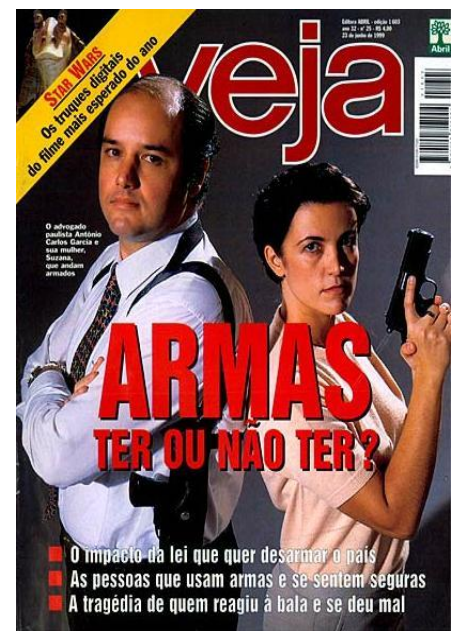

Fonte: Reprodução digitalizada de publicação impressa.

Nas duas edições, a relação com o fascismo social de Boaventura eclode com mais força quando "os direitos de cidadania, antes considerados inalienáveis, são confiscados - e, sem estes, os excluídos passam da condição de cidadãos à de servos. [...] As exclusões produzidas são radicais e inelutáveis, a tal ponto que os que as sofrem, apesar de formalmente cidadãos, são de fato excluídos da sociedade civil” (SANTOS, 1998). 
Segundo a posição do enunciador de Veja em edições de três décadas distintas, a sociedade tem o direito de se armar para se proteger. Esse direito, por aqui, é associado à lógica da liberdade que permeou e norteou o mesmo direito para cidadãos norte-americanos. O olhar do enunciador não se curva sequer à reflexão de uma lógica segundo a qual uma sociedade mais armada é, presumivelmente, uma sociedade mais propensa à violência. Uma das características do fascismo social é justamente o fato de que as pessoas vivam com medo e, apesar da democracia, não tenham assegurados direitos mínimos, como aquele à segurança.

Ainda de acordo com o sociólogo, "as relações sociais são fascistas porque um grupo social tem direito de veto sobre outros" (ALMANAQUE, 2001) e parte desse direito se estabelece justamente pela via do direito ao porte de armas, como no caso de facções criminosas. "Os grupos armados das favelas dizem às pessoas a que horas elas devem entrar, devem sair etc" (ALMANAQUE, 2001).

A revista dedicaria mais uma edição ao assunto após a votação do referendo, perfazendo as três diferentes capas sobre armas em 1984, 1999 e 2005. Desta vez, em 26 de outubro contrariada com a rejeição à ideia que ela defendera no plebiscito, no seguinte tom: "Depois do referendo, vamos ao que interessa: 7 soluções testadas e aprovadas contra o crime" (Fig. 7) (7 SOLUÇÕES, 2005, p. 1).

Figura 7 - Capa 7 soluções contra o crime, $\mathbf{n}^{0} 1928,2005$

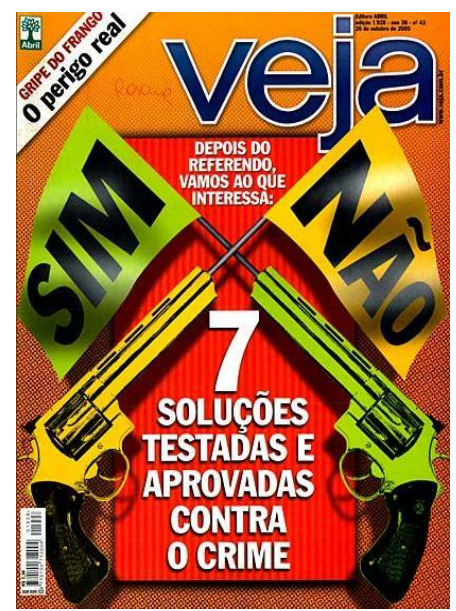

Fonte: Reprodução digitalizada de publicação impressa. 
O que está em jogo com uma pauta como essa depois da vontade popular ter expressado algo diferente do que a revista prescrevia? Está em jogo também a forma de discutir a autonomia do cidadão para se proteger da violência urbana, mesmo quando este direito é minoria numa consulta popular. Para isso, o enunciador constrói a moral do mais forte, do mais poderoso. "Aquele que busca vitória precisa de uma revista vitoriosa, de um enunciador potente, de opinião forte. É preciso apresentar e reapresentar a imagem do vitorioso" (PRADO, 2013, p. 115). Desta vez, Veja traz uma lista de medidas que obtiveram sucesso em outros estados e países - destaque para os Estados Unidos. "Em 1982, o estado da Califórnia, nos Estados Unidos, aprovou condenações mais longas para homicídios, estupros, assaltos a mão armada e roubos a residências e lojas. Em três anos, a criminalidade no Estado caiu 8\%. Sete anos depois, a queda chegou a 20\%" (7 SOLUÇÕES, 2005, p. 68).

Para a Veja, o capitalismo, como o direito à arma, representa uma outra força a ser, sempre que possível, enaltecida. Ao longo de décadas, mesmo diante de cenários econômicos marcados por profundas incertezas e que poderiam suscitar uma discussão mais ampla, Veja estava lá não apenas para assegurar a certeza da sobrevivência do sistema, mas a capacidade que ele teria de se reinventar e sair revigorado de intempéries globais.

Um breve exemplo está na reportagem de capa da edição de 15 de outubro de 2003, que discute o papel e a posição do Brasil na Alca (Área de Livre Comércio das Américas) ${ }^{7}$ com a chamada "Brasil peita os EUA na Alca - Coragem ou estupidez?" (BRASIL, 2003, p. 1). A imagem (Fig. 8) mostra um canário com uma faixa "Brasil" à cabeça, uma metáfora com a "seleção canarinho", chamando uma águia de tamanho e imponência colossais para a briga.

\footnotetext{
${ }^{7}$ Proposta lançada pelos Estados Unidos em 1994, durante a Cúpula das Américas - encontro que promove acordos comerciais. Foram assinados a Declaração de Princípios e o Plano de Ação para eliminar barreiras alfandegárias entre os 34 países, exceto Cuba, e formar uma área de livre de comércio.

${ }^{8}$ Depois da perda do Mundial de 1950, a CBD decidiu mudar as cores da seleção, que até então vestia branco. Um concurso foi promovido e o vencedor foi o gaúcho Aldyr Garcia Schlee. A nova camisa inspirou o radialista Geraldo José de Almeida a usar o termo "seleção canarinho".
} 
Figura 8 - Capa Coragem ou estupidez, n¹824, 2003.

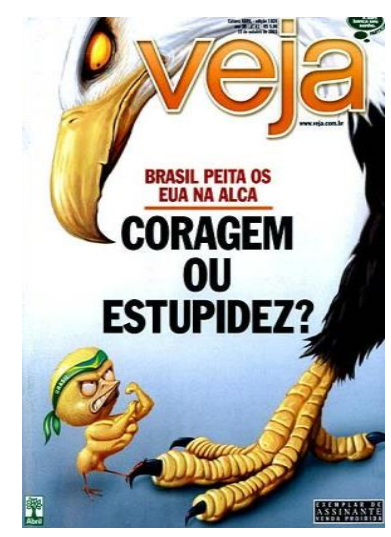

Fonte: Reprodução digitalizada de publicação impressa.

O enunciador indica que o Brasil está disposto a enfrentar, com o roteiro similar ao da jornada de um herói, ${ }^{9}$ um dos símbolos de uma nação que sempre enalteceu sua pujança econômica. A insensatez da valentia comercial tupiniquim surge no texto com uma ironia à esquerda.

Do ponto de vista de alguns diplomatas brasileiros conhecidos em Brasília como "as viúvas de Stalin", que estavam tendo exagerada e indevida influência nas negociações comerciais, tudo o que afaste o Brasil dos Estados Unidos é considerado um triunfo. $\mathrm{O}$ isolamento comercial seria apenas o preço a pagar para livrar o povo brasileiro da "anexação" ao império americano (BRASIL, 2003, p. 42).

A águia assume também a representação de algo a que se deve admirar.

\footnotetext{
${ }^{9}$ A obra A jornada do heroi é de Joseph Campbell, estudioso norte-americano de mitologia e religião. Nascido no dia 26 de março de 1904, na cidade de Nova York.
} 
Figura 9 - A imagem impressiona, n²250, 2012.

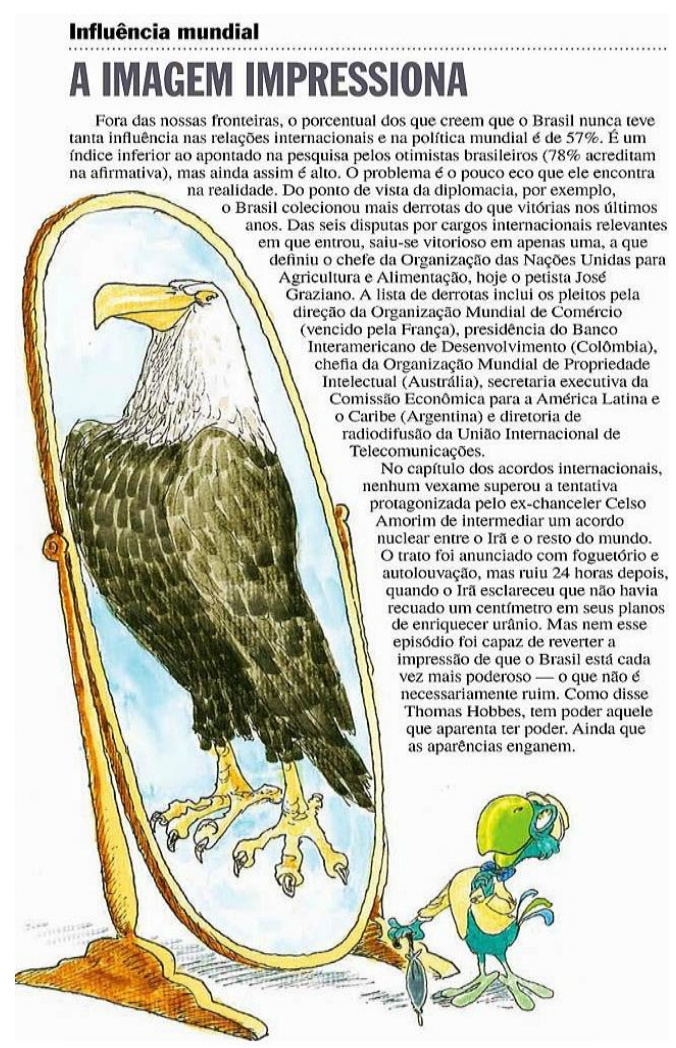

Fonte - Reprodução digitalizada de publicação impressa - do autor.

Ao colocar o papagaio em frente ao espelho para que ele observe e se veja refletido na águia, o enunciador assume um viés político, de subserviência ou idolatria à economia norteamericana (Fig. 9).

É possível identificar também formas bem distintas que o enunciador usa para estabelecer comparações entre os dois países. Para isso, é importante recorrer a uma fonte que traga, no bojo do seu discurso, elementos notadamente liberais como a capacidade de produzir e de cumprir metas.

Para o brasileiro, a virtude sempre esteve associada mais ao tempo e esforço despendidos no trabalho do que ao desempenho alcançado. Em países como os Estados Unidos, por exemplo, os fatores que contam são a produtividade e o cumprimento de metas", diz Jorge Arbache, professor de economia da Universidade de Brasília (MUITO, 2012, p. 74). 
Tudo que os Estados Unidos fazem, sobretudo nos aspectos sociais, políticos e econômicos, é voltado para o "bem" do mundo, de acordo com Veja. Ao Brasil, cabe um papel secundário de reverenciar o poder da mais importante economia e democracia do Ocidente. Em entrevista ao Le Monde Diplomatique Brasil (2007), Noam Chomsky ${ }^{10}$ explica que essa é uma estratégia para fixar uma ideologia:

Quando uma pessoa exerce poder sobre outra, seja um ditador, um colonizador, um burocrata, um patrão ou um marido, ela precisa de uma ideologia justificadora, que sempre redunda na mesma coisa: a dominação é exercida para "o bem" do dominado. Em outras palavras, o poder se apresenta sempre como altruísta, desinteressado, generoso (Grifo nosso) (MERMET, 2007).

Historicamente, Veja caminharia para se tornar mordaz combatente dos que ousam questionar o antiamericanismo. Um exemplo está na edição de 9 de agosto de 2006, na reportagem intitulada "O perfeito idiota paquistanês" (O GRANDE, 2006, p. 78). O primeiro parágrafo cita Noam Chomsky como alguém a quem a esquerda presta idolatria por críticas aos Estados Unidos.

No mercado internacional de ideias, o antiamericanismo vende bem. Não requer originalidade nem brilho - apenas uma cantilena contra George W. Bush e o imperialismo. Há intelectuais que ganham a vida explorando esse filão. O mais notório é o americano Noam Chomsky, mas o paquistanês Tariq Ali (que presta verdadeira idolatria a Chomsky) vem logo atrás (O GRANDE, 2006, p. 78).

O mesmo Noam Chomsky, agora sistematicamente criticado, fora bastante enaltecido na edição de 9 de julho de 1975. Veja trouxe, nas Páginas Amarelas, a entrevista com Chomsky, sob o título "Um linguista apaixonado pela política - o prestigiado professor americano discute os problemas do terceiro mundo" (VEJA, n. 357, 1975, p. 2).

$\mathrm{Na}$ abertura da entrevista, o enunciador afirma que Chomsky "costuma ser apontado como o mais importante linguista do mundo ocidental" p. 2), mas, devido a sua "militância política, pelas repercussões de seus livros não publicados no Brasil, transformou-se numa espécie de mito revolucionário para a juventude americana” (p. 2).

\footnotetext{
${ }^{10}$ Professor de linguística e filosofia no MIT (Massachusetts Institute of Technology).
} 
A postura refratária de Veja a Chomsky desenvolveu-se à medida que o linguista assumiu posições públicas contrárias aos imaginários-mesmos da publicação, ou seja, liberais. Segundo ele, a imprensa tenta passar uma imagem generosa, de um organismo social que trabalha a favor da verdade e do público, mas, na realidade, utiliza tais argumentos para justificar e manter o poder.

Charaudeau sugere que o debate nas mídias surge como meio de confrontar as opiniões para, depois, apresentar ao público sua versão. O autor explica que os veículos transformam determinado caso em espetáculo para, no final, converter opinião em julgamento.

Os debates que supostamente alimentam o espaço da discussão, confrontando opiniões diferentes e contrárias com o intuito de esclarecer o público, são apresentados como torneios oratórios, na verdade, espetáculos retóricos, que, ao final das contas, convertem as opiniões em julgamentos passionais. (CHARAUDEAU, 2009, p. 284).

A dimensão do debate, do compromisso social do jornalismo ao promovê-lo e do confronto de opiniões remete a outros casos em que a mesmidade prepondera em Veja. $\mathrm{Na}$ clássica edição de 23 de março de 1988, iniciou-se uma empreitada político-oligárquica do enunciador. $\mathrm{O}$ escolhido: um representante do poder que passa a ser apresentado à nação de forma heroica. O título da Editora Abril deu total suporte para que ele fosse visto desse modo. A chamada de capa: "Collor de Mello - O Caçador de Marajás” (Fig. 10) (COLLOR, 1988, p. $1)$. 
Figura 10 - O caçador de Marajás, nº1020, 1988.

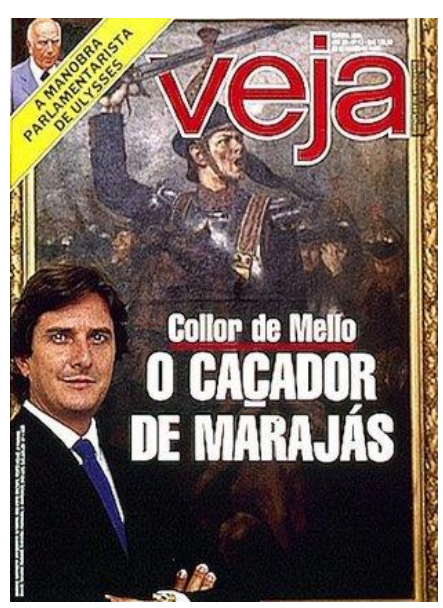

Fonte: Reprodução digitalizada de publicação impressa - do autor.

Naquele mesmo ano, em 6 de janeiro, Maílson da Nóbrega sucedia Bresser Pereira no comando da economia nacional. Nove dias depois, o Plano Verão era anunciado. "A inflação acumulada chegou a $1.037,50 \%$ no ano de 1988 , cenário ideal para que um político preocupado com a austeridade dos gastos públicos emergisse como antídoto" (MERMET, 2009). O caminho da primeira eleição direta para a presidência desde o golpe de 64 começava a ser construído: a Nova República, como fora chamado o governo Sarney, trouxe os ventos da abertura política, a consolidação do regime democrático, uma nova Constituição, mas não triunfou no combate à inflação e na redução das disparidades sociais. Era o momento certo para apresentar à sociedade alguém que, entre outras características, falasse com contundência da diminuição do Estado e do enfrentamento dos privilégios no setor público.

A reportagem de miolo recebe o título de "A Guerra ao turbante" (A GUERRA, 1988, p. 38). E a linha fina dela informa que Collor de Mello se tornara um dos governadores mais populares do País "no seu papel de caçador de marajás" (p. 38).

Chamado de "o gerente de Alagoas" já no fim do primeiro parágrafo do texto, a revista é categórica sobre Collor. "Ocorre que foi ele quem descobriu primeiro e usou melhor a mina de impacto político que pode ser aberta com uma boa caçada aos marajás do serviço público. Essa foi a sua maior obra e esse é o seu segredo" (p. 38). Na mesma página, outro trecho de exaltação: "Collor de Mello assumiu o comando com a promessa de devastar os holerites acintosos de 300 funcionários estaduais que recebiam fortunas através de expedientes legais 
marotos. Cumpriu o compromisso e descobriu que tinha uma fascinante briga nas mãos" (COLLOR, 1988, p. 38).

Três expressões no trecho acima chamam a atenção. A primeira é o desafio: "devastar os holerites acintosos". A segunda está no uso da antítese - “expedientes legais marotos". A terceira, de pura exaltação, explica que Collor já cumprira tal compromisso, que se tornara uma "briga fascinante". Veja de 23 de março de 1988 ainda cita que Collor, "como caçador, conquistou reputação de político preocupado com a moralidade" (COLLOR, 1988, p. 39). Uma explicação breve que remete à questão acima citada, das "fortunas através de expedientes legais marotos", aparece num trecho da página 40. "Será sempre obrigatório concluir que o povo aplaude Collor de Mello porque ele fala contra privilégios de funcionários aproveitadores e combate abusos que, no fim da linha, são pagos pelo bolso do contribuinte. E os contribuintes, no Brasil, estão cansados de ser explorados" (COLLOR, 1988, p. 40).

Outro detalhe chama a atenção: o volume de apostos para qualificá-lo. Na capa, "O Caçador de Marajás". Na abertura da matéria, o "gerente de Alagoas”. E há mais.

Esse senhor, herdeiro de boa fortuna e mimado pelo ambiente aconchegante de uma família endinheirada, tinha tudo para avançar pela vida como um desses eternos garotões de praia e de vida noturna. Em vez disso, acabou combatendo marajás, desafiando a aristocracia dos usineiros alagoanos e prometendo passar a limpo a tradição de violência em seu Estado (COLLOR, 1988, p.41).

Cremilda Medina (2008) explica que a escolha de uma fonte é um processo autoritário, em especial quando se busca contemplar interesses ou validar um cenário preexistente.

Ponto de partida da entrevista, a escolha da fonte de informação está associada à própria pauta. Dentro de um processo autoritário (a ditadura da oferta), esta seleção preexiste a uma pesquisa de campo. A predeterminação de quem se deve ouvir na reportagem é inerente ao jornalismo acoplado a grupos de poder (econômico ou político ou cultural) (MEDINA, 2008, p. 35).

De acordo com o dicionário Aurélio, a palavra marajá deriva do sânscrito (maharaja, que significa grande rei). De forma figurada, ele é sinônimo de homem muito rico ou de pessoa que exerce ou exerceu cargo público com salário vultoso.

Nas eleições presidenciais, o enunciador mostra o candidato Fernando Collor de Melo como o símbolo de uma campanha em que os valores-mesmos de Veja estão representados. 
Para isso, constrói e alimenta a repulsa pelo principal adversário de Collor (Fig. 11). No estudo sobre as construções da imagem do presidente Lula nas reportagens de capa de Veja durante a campanha presidencial de 1989, por exemplo, Dalva Ramaldes e Aidar Prado (2008) identificaram que Collor de Melo foi construído não como candidato que se opõe a Lula, mas como "candidato do não".

Figura 11 - Capa Presidente Collor ou Presidente Lula, nº1106, 1989.

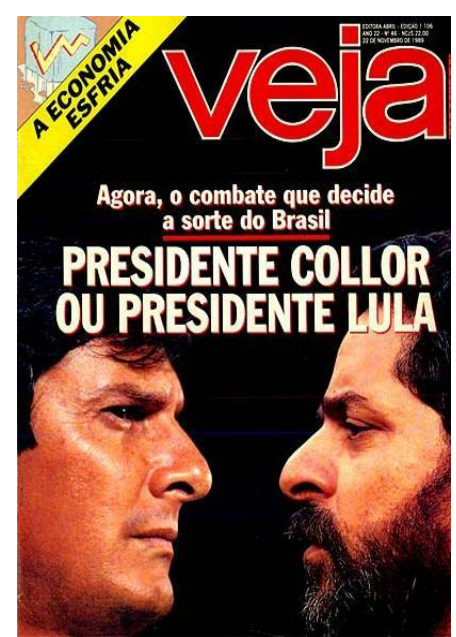

Fonte: Reprodução digitalizada de publicação impressa.

Intitulada "A briga pela faixa" (A BRIGA 1989, p. 48), a matéria indica que "no confronto final, o metalúrgico Lula e o ex-governador Collor terão de mostrar ao eleitor quem é o verdadeiro candidato do não" (A BRIGA 1989, p. 48). Nas linhas seguintes, o enunciador aponta que, no primeiro turno, os eleitores apostaram "nos candidatos que lhes pareceram mai adequados ao papel de demolidor" (A BRIGA 1989, p. 48) e pontua que esses dois candidatos "pouco têm a ver com o mundo enrugado da política tradicional” (A BRIGA 1989, p. 48).

De acordo com Ramaldes e Prado (2008), a estratégia discursiva foi a de "diluir a oposição no plano político, evitando relacionar os dois projetos aos contextos da política brasileira, em que Collor estaria colocado no pódio da política conservadora das elites e Lula na perspectiva de uma política de transformação" (PRADO, 2008, p. 168). Para isso, segundo os autores, a oposição é deslocada para outros tópicos temáticos em vários níveis. É o que ocorre 
nas legendas das fotos, como mapearam Ramaldes e Prado (2008). Nelas, os dois candidatos são apresentados da seguinte forma (Quadro 2).

\section{Quadro 2 - Candidatos e Oposições de Veja.}

\begin{tabular}{l|l|}
$\begin{array}{l}\text { Collor tem formação universitária } \\
\text { Teve pai senador }\end{array}$ & $\begin{array}{l}\text { Lula foi retirante nordestino, seu diploma é } \\
\text { de madureza ginasial }\end{array}$ \\
\hline $\begin{array}{l}\text { Já foi prefeito, deputado e governador } \\
\begin{array}{l}\text { Construiu sua candidatura sozinho } \\
\text { montado numa legenda alugada }\end{array}\end{array}$ & Apóia-se na militância do PT \\
\hline $\begin{array}{l}\text { Pregando caça aos marajás, martelando os } \\
\text { políticos tradicionais e o governo Sarney } \\
\text { Ganhou disparado }\end{array}$ & $\begin{array}{l}\text { É apoiado pela esquerda } \\
\text { Conseguiu vencer Brizola, político tradicional }\end{array}$ \\
\hline
\end{tabular}

Fonte: Reprodução digitalizada de publicação impressa - do autor.

No estudo sobre as edições seguintes, Ramaldes e Prado (2008, p. 168) identificaram que o candidato Collor de Melo foi tomado como modelo. [...] "tem corpo adequado em largura e altura, com porte e força, com preparo intelectual e berço. A figura de Collor em geral assumirá um ar de guerreiro, de transformador que encara o jogo pesado da política" (Fig. 12).

Figura 12 - Capa Collor, $\mathbf{n}^{0} 1108,1989$.

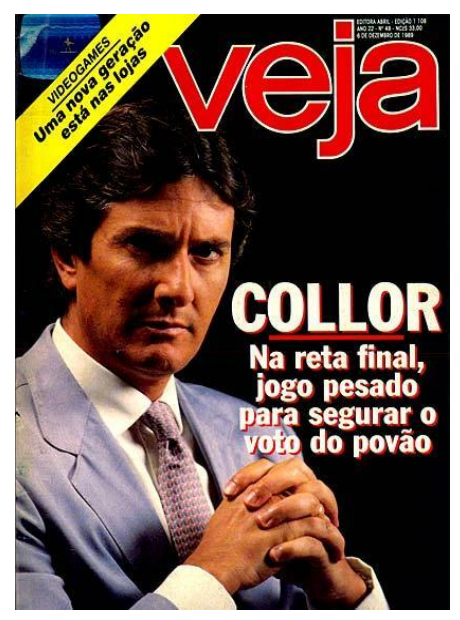

Fonte: Reprodução digitalizada de publicação impressa. 
Ramaldes e Prado (2008) também destacam que, na primeira eleição direta para presidência depois da ditadura militar (1964-1985), Collor era um candidato desacreditado, mas ganhou notoriedade após o apoio da mídia e dos empresários - Organizações Globo e Editora Abril. O presidente da Editora Abril, Roberto Civita, admite o apoio num vídeo ${ }^{11}$.

\begin{abstract}
Nós conhecemos o Collor. Um dia ele veio, ainda governador de Alagoas, nos visitar em São Paulo. A gente nunca tinha visto o Collor. Eu juntei o diretor da revista, dois editores da política; éramos meia dúzia para receber o Collor, para falar e ouvi-lo. E ele foi brilhante. Foi genial. Foi maravilhoso. A gente ficou absolutamente, como se fôssemos meninas de 18 anos, embasbacados com esse cara (ROBERTO, 2007).
\end{abstract}

Civita revela que a decisão de trazer Collor na capa surgiu após essa visita. “Resolvemos dar uma capa com ele, com o título 'O Caçador de Marajás’ porque ele nos contou que tava acabando com os marajás da política em Alagoas" (ROBERTO, 2007). Civita admite não ter verificado todas as informações dadas por Collor, mas que publicou o que parecia certo.

Após a campanha presidencial, a vitória de Collor, a posse, o pacote anti-inflacionário, o presidente da Editora Abril diz ter percebido que havia corrupção no governo. Segundo ele, foram quatro meses de capas semanais sobre "o esquema PC Farias e a roubalheira do governo federal. Então, esta foi uma série de capas da qual me orgulho muito porque acho que a Veja prestou um grande serviço ao país" (ROBERTO, 2007).

\title{
Considerações finais
}

Vimos que para a construção do interesse social que o jornalismo pressupõe, todo discurso depende das condições específicas da situação de troca, segundo Patrick Charaudeau (2009). Charaudeau explica que o reconhecimento das condições de realização de troca linguageira resulta em um "contrato de comunicação" em que o enunciador assume posições discursivas apresentadas de modo positivado ou, como define Prado (2013), se põe como sabedor. Como já indicado por Ernesto Laclau e Chantal Mouffe (2015), o discurso é uma tentativa de dominar o campo da discursividade e deter o fluxo das diferenças, construindo um centro. Para isso, como explica Prado (2013), o discurso amplia as cadeias significantes que

\footnotetext{
11 "Roberto Civita X Collor de Mello" é o nome do vídeo postado no Canal “veja.com", no Youtube, em 26 de dezembro de 2007. Nele, Civita fala sobre as capas de Veja sobre Fernando Collor de Mello.
} 
buscam fixar os sentidos. De acordo com Prado (2013), os pontos nodais fixam os sentidos ao criar a identidade de um discurso pela construção de um nó. Na concepção de Laclau e Mouffe (2015), pontos nodais são "os pontos discursivos privilegiados desta fixação parcial” (p. 178). É por este motivo que, como afirma Prado (2013a), a sociedade nunca conseguirá ser igual a si mesma, "pois a articulação constrói pontos nodais que fixam apenas parcialmente o sentido" (PRADO, 2013, p. 99).

O estudo identificou como pontos nodais que Veja utilizou para classificar seus valoresmesmos as palavras: progresso, liberdade, modernidade, desenvolvimento, força, vigor e inspiração. Nos valores-mesmos estão as principais marcas e diretrizes do pensamento liberal norte-americano em torno do capitalismo, do liberalismo econômico e os pontos nodais liberdade e prosperidade. Do ponto de vista político, a lógica da colonização. O Brasil só será uma grande nação se andar par e passo com os Estados Unidos, espelhando-se no modelo político deles e na liderança global. A pesquisa percebeu também que são afastadas do espaço dos valores-mesmos de Veja, por exemplo, as figuras do criminoso, sem-terra, árabe, do excluído e do miserável.

\section{Referências}

7 PERIGOS de dar uma banana para a Alca. Veja. São Paulo: Editora Abril, edição n. 1824, 2003.

7 SOLUÇÕES contra o crime. Veja. São Paulo: Editora Abril, edição n. 1928, 2005.

7 RAZÕES para votar NÃO. Veja. São Paulo: Editora Abril, edição n. 1925, 2005.

A BRIGA pela faixa. Veja. São Paulo: Editora Abril, edição n. 1106, 1989.

A FEBRE paralisante. Veja. São Paulo: Editora Abril, edição n. 870, 1985.

AGORA, o combate que decide a sorte do Brasil - presidente Collor ou presidente Lula. Veja. São Paulo: Editora Abril, edição n. 1106, 1989.

A GUERRA ao turbante. Veja. São Paulo: Editora Abril, edição n. 1020, 1988.

ALMANAQUE. Dinheiro. Cronologia. Folha Uol. 2009. Disponível em:< http://almanaque.folha.uol.com.br/dinheiro80.htm>. Acesso em: 14 de jul. 2015. 
ARMAS - ter ou não ter? Veja. São Paulo: Editora Abril, edição n. 1603, 1999.

ASSALTOS, medos e autodefesa - O brasileiro se arma. Veja. São Paulo: Editora Abril, edição n. 822, 1984.

BELMONTE, Wagner. A construção da relação "Brasil - Estados Unidos" na revista Veja. 216. 408 f. Tese (Doutorado em Comunicação e Semiótica) - Pontifícia Universidade Católica de São Paulo, São Paulo, 2014.

BENETTI, Marcia. A ironia como estratégia discursiva da revista Veja. Líbero, São Paulo, Ano X, n. 20, 2007.

BRASIL peita os EUA na Alca - Coragem ou estupidez? Veja. São Paulo: Editora Abril, edição n. 1824, 2003.

CALDEIRA, Tereza. Regimes de visibilidades do outro. In: PRADO, José Luiz Aidar et al. A invenção do mesmo e do outro na mídia semanal. São Paulo: PUC-SP, 2008. 1 DVD hipermídia.

COLLOR de Mello - O caçador de marajás. Veja. São Paulo: Editora Abril, edição n. 1020, 1988.

CHARAUDEAU, Patrick. Discurso das mídias. São Paulo: Contexto, 2009.

DE braços cruzados. Veja. São Paulo: Editora Abril, edição n. 868, 1885.

DEPOIS do referendo, vamos ao que interessa: 7 soluções testadas e aprovadas contra o crime. Veja. São Paulo: Editora Abril, edição n. 1928, 2005.

ENTUSIASMO até o fim. Veja. São Paulo: Editora Abril, edição nº 1145, 1990.

FERREIRA, Fabio Alves. Para entender a teoria do discurso de Ernesto Laclau. REVISTA ESPAÇO ACADÊMICO, Maringá, Ano XI, n. 127, 2011.

FHC encara a CUT. Veja. São Paulo: Editora Abril, edição n. 1393, 1995.

FHC peita a CUT. Veja. São Paulo: Editora Abril, edição n. 1394, 1995.

IKEHARA, Hideharu Carlos Ikehara. A reserva de mercado de informática no Brasil e seus resultados. REVISTA DE CIÊNCIAS HUMANAS DA UNIPAR. Umuarama: 1997, v. 5, n. 18, 1997, p. 7-21.

LACLAU, Ernesto; MOUFFE, Chantal. Hegemonia e estratégia socialista - por uma política democrática radical. São Paulo: Intermeios, 2015.

MEDINA, Cremilda. Entrevista: o diálogo possível. São Paulo: Ática, 2008. 
MEMÓRIAS de um editor. Veja. São Paulo: Editora Abril, edição n. 2324, 2013.

MERMET, Daniel. América Rebelde: uma entrevista com Noam Chomsk. Le monde diplomatique Brasil. 2007. Disponível em: <

https://www.diplomatique.org.br/print.php?tipo=ar\&id=2>. Acesso em: 12 de jul. 2015.

MUITO suor, pouca produção. Veja. São Paulo: Editora Abril, edição nº 2250, 2012.

O GRANDE duelo no mundo comunista. Veja. São Paulo: Editora Abril, edição n. 1968, 2006.

O PLANALTO sacou primeiro. Veja. São Paulo: Editora Abril, edição n. 1396, 1995.

O TESTE das greves. Veja. São Paulo: Editora Abril, edição n. 870, 1985.

PRADO, José Luiz Aidar. Convocações biopolíticas dos dispositivos comunicacionais. São Paulo: EDUC: FAPESP, 2013.

PRADO, José Luiz Aidar. Linhas de fuga, da mídia semanal à hipermídia: é possível educar para as mídias? Intexto, Porto Alegre, v. 2, n. 15, 2006.

RAMALDES, Dalva; PRADO, José Luiz Aidar. O corpo do poder: estudo semiótico da figura de Lula na campanha presidencial de 1989 nas revistas semanais Veja e Istoé. BRAZILIAN JOURNALISM RESEARCH, Brasília, v. 1, n. 1, p. 167-189, 2008.

REBELIÃO na galáxia vermelha. Veja. São Paulo: Editora Abril, edição n. 1968, 2006.

REFERENDO da fumaça. Veja. São Paulo: Editora Abril, edição n. 1925, 2005

ROBERTO Civita - (1936-2013). Veja. São Paulo: Editora Abril, edição n. 2324, 2013.

ROBERTO Civita X Collor de Mello. Veja. São Paulo: Vejapontocom, 2007. Acesso em: 28 de jul. 2015.

SANTOS, Boaventura de Sousa. Entrevista da $2^{\text {a }}$. Democracia convive com fascismo social. Folha Uol. 2001. Disponível em: < http://www1.folha.uol.com.br/fsp/brasil/fc2105200102.htm>. Acesso em: 09 jul. 2015.

SANTOS, Boaventura de Sousa. O fascismo como regime social. Carta Maior. 2003. Disponível em: <

http://www.cartamaior.com.br/colunaImprimir.cfm?cm_conteudo_idioma_id=19422 >. Acesso em: 10 jul. 2015.

SANTOS, Boaventura de Sousa. Os fascismos sociais. Folha Uol. 1998. Disponível em: < http://www1.folha.uol.com.br/fsp/opiniao/fz06099808.htm>. Acesso em: 09 jul. 2015.

SINAIS de boa vontade. Veja. São Paulo: Editora Abril, edição n. 940, 1986. 
TRONTI, Mario. A teoria política do individualismo possessivo: de Hobbes até Locke. In: Hegemonia e estratégia socialista - por uma política democrática radical. São Paulo: Intermeios, 2015.

UM linguista apaixonado pela política. Veja. São Paulo: Editora Abril, edição n. 357, 1975.

Wagner Belmonte - Faculdade de Paulus de Tecnologia e Comunicação - FAPCOM. São Paulo | SP | Brasil. Contato: wagnerbelmonte@yahoo.com.br

Artigo recebido em maio de 2017 e aprovado em junho de 2017 